\title{
COMUNICAÇÃ̃O
}

\section{AUSÊNCIA DE LESÃO CARDÍACA ATRIBUTIVEL AO TRYPANOSOMA CRUZI, PELO MENOS APÓS DEZESSETE ANOS DE DECURSO DE DOENÇA DE CHAGAS TRANSFUSIONAL}

\author{
Vicente Amato Neto, Maria de Lourdes Higuchi e Valdir Sabbaga Amato
}

Em julho de 1977, um de nós foi procurado por paciente com 19 anos de idade, acometido de talassemia "major" e, através dos anos, receptor de muitas transfusões de sangue. $\mathrm{Na}$ ocasião, estavam presentes febre e enfartamento de linfonodos, além de anormalidades relacionadas com a doença antes citada e constituídas sobretudo por anemia, hepatomegalia e sopro sistólico audivel nos vários focos de ausculta. Foi estipulado o diagnóstico de toxoplasmose adquirida, forma ganglionar, sendo que essa infecção pôde ser satisfatoriamente tratada.

Com intuito especulativo, houve solicitação de algumas provas sorológicas e, entre elas, as pertinentes à doença de Chagas, efeturadas em conceituada instituição privada da cidade de São Paulo (Laboratório Fleury; Rua Cincinato Braga, 282). Esses exames indicaram positividades e corresponderam aos seguintes: fixação do complemento (1/128), hemaglutinação passiva (1/20480), imunofluorescência indireta $(++++)$ e imunofluorescência para evidenciação de anticorpos IgM (não reagente). Houve comunicação do ocorrido ao médico-assistente do doente, com o qual não sucedeu qualquer contato posterior.

Decorridos 17 anos e, mais precisamente, no mês de janeiro de 1994, teve lugar internação do enfermo no Instituto do Coração do Hsopital das Clínicas, da Faculdade de - Medicina da Universidade de São Paulo, em virtude de grave insuficiência cardíaca. Diante da impossibilidade de compensação por meio dos recursos terapêticos convencionais,

\footnotetext{
Departamento de Doenças Infecciosas e Parasitárias e Instituto do Coração do Hospital das Clínicas, da Faculdade de Medicina da Universidade de São Paulo, São Paulo, SP. Endereco para correspondência: Prof. Vicente Amato Neto. Av. Dr. Enéas de Carvalho Aguiar 255, 05403-900 São Paulo, SP, Brasil.
}

Recebido para publicação em 21/10/94. procedeu-se a transplante de coração, ficando assim viável exame anatomopatológico do coração. Como, de acordo com o laudo adiante apresentado, não se evidenciou qualquer alteracão atribuivel ao Trypanosoma cruzi, consideramos adequado consignar esta comunicação.

Exame anatomopatológico do coração. Peso: 500g; dimensões: $12 \times 12 \times 10 \mathrm{~cm}$ nos maiores eixos; forma globosa e consistência diminuída; epicárdio liso e brilhante; à abertura, observa-se moderada dilatação e discreta hipertrofia dos ventrículos; o miocárdio tem cor castanho-ferruginosa, semáreas macroscópicas de afilamento ou fibrose; as valvas são normais; as coronárias mostram paredes delicadas e luz ampla; cortes histológicos representativos demonstram miocárdio com acentuada hipertrofia das fibras cardíacas, nas quais há intenso depósito de pigmento férrico, discreta fibrose intersticial, fibroblastos e histiócitos; não estão presentes sinais histopatológicos de miocardite em atividade (Figura 1).

Os aspectos macro e microscópicos são compativeis com doença cardíaca por hemossiderose. Não há sinais de miocardite atual ou pregressa e, macroscopicamente, inexistem evidências sugestivas de associação com doença de Chagas.

É conveniente aduzir que biópsias endomiocárdicas, pós-transplante, evidenciaram rejeição aguda mista, celular e humoral, no vigésimo primeiro dia, que regrediu com medidas terapêuticas adequadas, e rejeição aguda celular no segundo mês. Em nenhum momento sucedeu encontro das alterações histológicas de reativação da doença de Chagas.

Comentários. A infecção pelo T. cruzi revelada por exames sorológicos confiáveis, só pode ter sido motivada por transfusão de sangue, pela impossível influência de outras 
Comunicação. Amato Neto V, Higuchi ML, Amato VS. Ausência de lesão cardiaca atribuíuel ao Trypanosoma cruzi, pelo menos após dezessete anos de decurso de doença de Chagas transfusional. Rerista da Sociedade Brasileira de Medicina Tropical 28:415-417. out-dez, 1995.

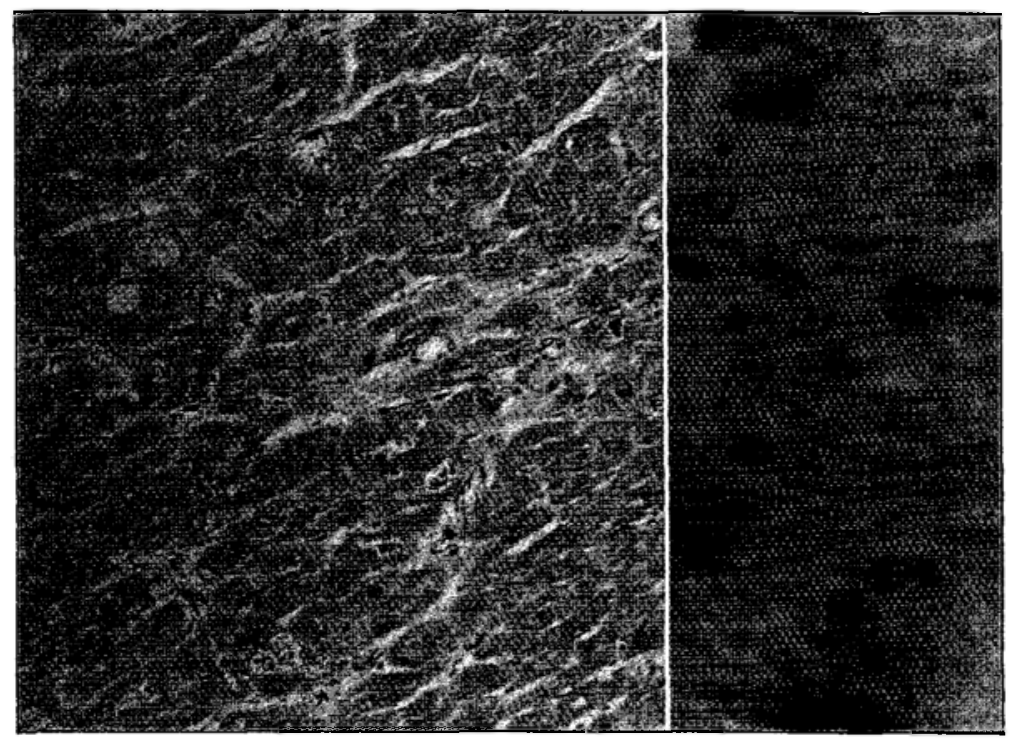

Figura 1 - À esquerda, aspecto microscópico do miocärdio. mostrando intenso acumulo de pigmento de bemossiderina intracelular: discreta fibrose e moderada reatividade bistiocitâria intersticial: ausência de miocardite (HE. $100 x$ ). Á direita, coloraça especifica evidenciando ferro intracelular (Perls. 400x).

modalidades de transmissão. Essas provas foram executadas em instituição considerada bastante eficiente e não vemos como valorizar eventuais reações cruzadas, pois a afecção básica era a talassemia, com hemossiderose, presente a despeito do muito prolongado uso terapêutico do mesilato de deferoxamina.

É lógico que a circunstância possibilitadora desta observação não corresponde a algo inédito. Infectado conhecido pode vir a morrer em virtude de ocorrências diversas, acidentais por exemplo, e suceder autópsia. Porém. não constitui fato freqüente, disso derivando nosso relato.

É preciso ressaltar que no coração de individuos com doença de Chagas assintomática em vida, depois de morte súbita ou acidental são vistas, macro e microscopicamente, lesões muito semelhantes às encontradas quando examinado o órgão dos falecidos em seguida a período de insuficiência cardíaca. Isso contrasta, então, com o fato que agora referimos.

Não sabemos quando houve a infeccão, mas ela esteve vigente pelo menos durante dezessete anos e a análise anatomopatológica do coraçào é interpretável como detalhada e satisfatoria. Prevaleceu cabalmente o diagnóstico de hemossiderose, suspeitado e valorizado clinicamente, tendo a miocardiopatia parasitária apenas merecido especulação.

Vários aspectos clínico-evolutivos da doença de Chagas estão estabelecidos. Não obstante, há questões que ainda suscitam melhores esclarecimentos, como a mais completa demarcação dos fatores influentes no decurso do processo, sendo cogitada a virulência de cepas, reinfecções, atividade física e outras contingências. Também particularidades da forma indeterminada, envolvendo definição, período de duração e elementos precipitandes da passagem para etapa com claros comprometimentos orgânicos, comumente merecem abordagens ${ }^{14}$.

O que agora mencionamos mostra uma peculiaridade, ou seja, a total ausência de lesão cardíaca mesmo tendo razoavelmente longo decurso a parasitose, conforme o exame anatomopatológico demonstrou, em paciente cujas condições clínicas permitiram ilustrativa observação.

\section{REFERÊNCIAS BIBLIOGRÁFICAS}

1. Almeida JWR, Shikanai-Yasuda MA, Amato Neto V. Castilho EA, Barreto ACP. Estudo da forma 
Comunicação. Amato Neto V, Higucbi ML, Amato VS. Ausência de lesão cardíaca atribuível ao Trypanosoma cruzi, pelo menos após dezessete anos de decurso de doença de Chagas transfusional. Revista da Sociedade Brasileira de Medicina Tropical 28:415-417, out-dez, 1995.

indeterminada da doença de Chagas através da eletrocardiografia dinâmica. Revista do Instituto de Medicina Tropical de São Paulo 24:222-228, 1982.

2. Amato Neto V. Doença de Chagas póstransfusional. Revista do Hospital das Clínicas da Faculdade de Medicina da Universidade de São Paulo 43:135-137, 1988
3. Lopes ER, Chapadeiro E, Almeida HO, Rocha A. Contribuição ao estudo da anatomia patológica dos corações de chagásicos falecidos subitamente. Revista da Sociedade Brasileira de Medicina Tropical 9:269-282, 1975.

4. Macêdo V. Forma indeterminada da doença de Chagas. Jornal Brasileiro de Medicina 38:34-40, 1980. 